\title{
Morphometric and elemental microanalytical studies of human lung in health and disease
}

\author{
K A SIEGESMUND, ${ }^{1}$ A FUNAHASHI, ${ }^{2}$ AND D E YORDE ${ }^{3}$ \\ From the Departments of Anatomy, ${ }^{1}$ Medicine,${ }^{2}$ and of Anatomy and Pathology, ${ }^{3}$ Medical College of \\ Wisconsin, Milwaukee, Wisconsin 53226, USA
}

ABSTRACT Current methods for determining the fibrogenicity of substances are based on relatively long term exposures of animals to the substance and the evaluation of morphological changes occurring in the lung. The use of inhalation chambers, which produce a more physiological environment, suffer from the need for particularly long exposure times (1-3 years). The present study describes a technique using scanning electron microscopy, energy dispersive analysis, and a digitiser pad with a computer to evaluate the fibrogenicity of silica in cases of known exposure. Scanning electron micrographs taken from silicotic lungs were evaluated for the degree of thickening (fibrosis) and the same areas were analysed for silicon content. Correlations between silicon content and septal thickening were shown to be significant $(p<0.0001)$. The study also describes the concentrations of elements found in normal lungs. The technique for establishing correlation curves between elemental concentrations and septal thickening could be of value in determining the fibrogenicity of pure substances after short exposures in an environmental chamber.

One of the primary morphological changes observed in fibrotic lung disease due to inhalation of inorganic dust, such as silica, is a pronounced thickening of the interalveolar septa. The thickening is associated with the deposition of large quantities of collagen fibres among the cells of the septa. It is thought that the fibres are laid down by one of two processes. A "fibrogenic" agent may act directly on the fibroblast stimulating it to produce large quantities of collagen or the cell may also be stimulated by substances released from dying macrophages that have ingested excessive amounts of non-digestible substances. ${ }^{1-6}$ In either case the agent responsible directly, or indirectly, for fibroblast stimulation is considered to be fibrogenic.

Several methods are available for assessing the fibrogenicity of a substance. The haemolysis of red blood cells is one method that has been used, ${ }^{7-9}$ although a recent study has shown that this is not always predictive of fibrosis. ${ }^{1011}$ Other methods involve the determination of the cytotoxicity of the suspected substance..$^{12-14}$ This procedure also appears to correlate poorly with fibrosis and is not

Received 14 November 1984

Accepted 23 January 1984 recommended as the sole method for determining fibrogenicity..$^{115}$

In vivo methods for determining fibrogenicity of substances are based on the instillation of substances, such as silica, into the trachea of experimental animals. ${ }^{16-18}$ After a period of 6-12 months the lungs are examined for either biochemical or histological alterations. Inhalation studies for determining fibrogenicity, although more physiological, need long exposures in chambers (1-3 years) before current methods can detect significant changes in the lung. ${ }^{1920}$

Biochemical methods involve the assay of lung hydroxyproline which is considered to be indicative of collagen sythesis..$^{21-23}$ Histological methods are considered the most reliable means of determining whether or not a substance is fibrogenic. ${ }^{1124}$ It is generally agreed that the presence of thickened septa together with interstitial exudate and epithelial metaplasia are features characteristic of pulmonary fibrosis. A substance can be evaluated for its fibrogenicity by exposing animals to known concentrations of the pure substance and observing for any of these changes. Both instillation techniques (6 months -1 year) and inhalation techniques (1-3 years) require long periods of exposure before significant changes can be observed in the lung. 
The examination of human lungs from workers exposed to various substances does not always permit the establishment of a "cause and effect" relation between a particular substance and fibrosis. The detection of a foreign element in the fibrotic lung tissue does not necessarily establish the aetiological role of that element. If, however, a positive correlation is observed between the amount of substance in the tissue and the degree of fibrosis then a possible aetiological role for that substance may be suggested.

The present study describes a procedure using scanning electron microscopy and energy dispersive analysis together with morphometry to quantitate small areas of fibrosis with known concentrations of elements found within the fibrotic areas. A dose response relationship may then be implicated between the foreign substance and the septal thickening. In addition, normal levels for various elements found in lungs of individuals without evidence of pulmonary disease were determined.

\section{Materials and methods}

\section{SPECIMEN PREPARATION}

Lung tissue from normal controls and established cases of silicosis with interstitial fibrosis were examined in the scanning electron microscope (SEM) and analysed by energy dispersive $x$ ray analysis. The individuals chosen as normal controls had no known clinical or histological evidence of lung disease. Sections were cut from paraffin blocks, stained with haematoxylin and eosin, and examined in a light microscope. Thirty micrometer sections of tissue showing areas of varying degrees of fibrosis were cut from these blocks. The sections were treated with xylene to remove the paraffin and hydrated by passage through decreasing concentrations of alcohol and into distilled water. The sections were floated from the distilled water on to the surface of spectroscopically pure carbon planchets. The samples were coated with a $100 \AA$ layer of carbon by vapour deposition.

\section{SEM EXAMINATION}

The planchets containing the sections were examined in a JSMU 35 scanning electron microscope. Areas of thickened septa, selected to be free of any obvious vessels, pleura, bronchi, or nodules were photographed at $100 \times($ fig 1$)$ and an energy dispersive $\boldsymbol{x}$ ray analysis was carried out. The areas photographed and analysed were about $1 \mathrm{~mm}$ in size. A total of five areas was photographed and analysed for each patient or normal control examined. A nuclear semiconductor $152 \mathrm{eV}$ resolution $\mathrm{Si}(\mathrm{Li})$ detector and a Tracor Northern NS880

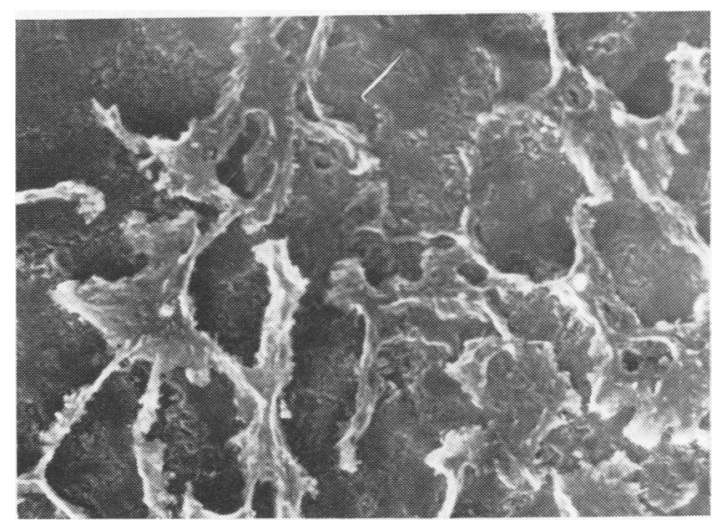

Fig 1 Scanning electron micrograph of a 30 micrometer thick section of human lung. ( $\times$ 100.)

computer base data handling system were used for the analyses. The specimen detector distance was $2.85 \mathrm{~cm}$ at 0 degree tilt and a takeoff angle of $37^{\circ}$. All spectra were stored on magnetic tape for future reference. Each area was analysed for 100 seconds at a $25 \mathrm{kv}$ operating potential and a specimen current of $3 \times 10^{-10}$ amps.

\section{DATA REDUCTION AND USE OF}

ELEMENT/SULPHUR RATIOS

The relative abundance of each element was calculated from an analysis of the counts generated for a given element by comparison with the reference spectra of the materials containing known concentrations of that element. Concentration ratios were calculated and corrected for absorption, fluorescence, and atomic number effects, assuming carbon

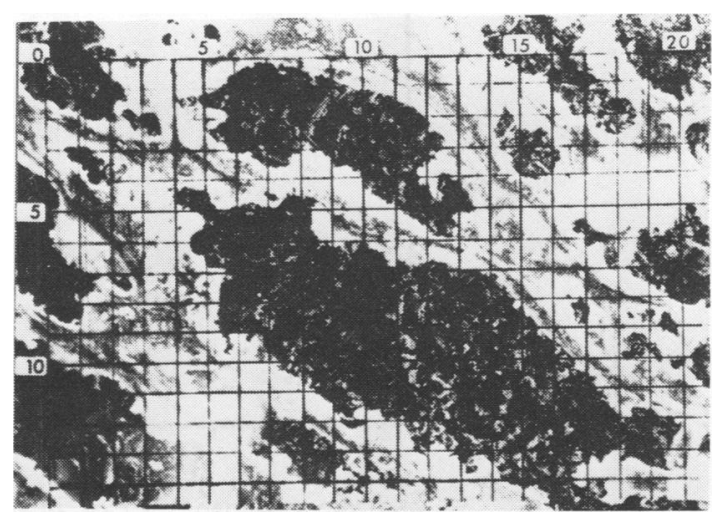

Fig 2 Scanning electron micrograph of human lung section with transparent grid overlay (black lines) used to select random $X, Y$ coordinates. 


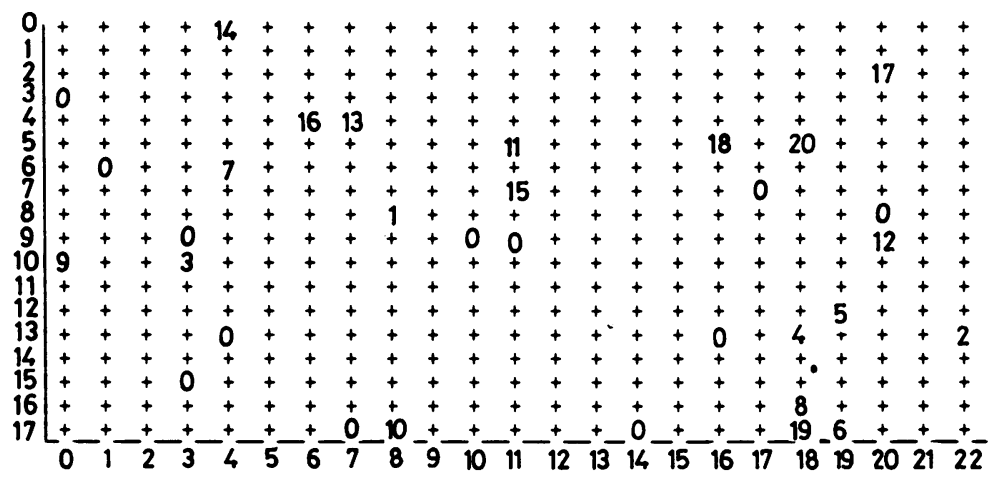

\begin{tabular}{|c|c|c|c|}
\hline $\begin{array}{l}\text { Picture No } \\
\text { experiment }\end{array}$ & $\begin{array}{l}8622 \\
\text { Example }\end{array}$ & & \\
\hline $\begin{array}{r}49.13 \\
106.21 \\
19.53 \\
27.76 \\
183.84\end{array}$ & $\begin{array}{r}44.58 \\
109.45 \\
106.48 \\
36.47 \\
121.23\end{array}$ & $\begin{array}{r}44.66 \\
130.47 \\
70.75 \\
57.26 \\
104.19\end{array}$ & $\begin{array}{r}103.41 \\
50.90 \\
121.56 \\
68.78 \\
69.44\end{array}$ \\
\hline
\end{tabular}

Fig 3 Cathode ray tube display of grid system with 20 individual measurements of septa. Numbers on grid indicate location of each measurement.

as a back ${ }_{5}$-nund. Because of the difficulties inherent in determining the exact amount of material examined, the data were presented as relative elemental concentrations by weight.

The use of Si/S ratios was necessary because of the structural characteristics of lung tissue and because of slight differences in section thickness. A previous study using regression analyses on sections of vary- 8 ing thickness has shown that sulphur may be used as a reliable indicator of tissue mass, and that a $\mathrm{Si} / \mathrm{S}$ ratio gave a more valid indication of silicon concen- $\stackrel{P}{?}$ tration than silicon alone. ${ }^{25} 26$ Based on $\mathrm{Si} / \mathrm{S}$ ratios

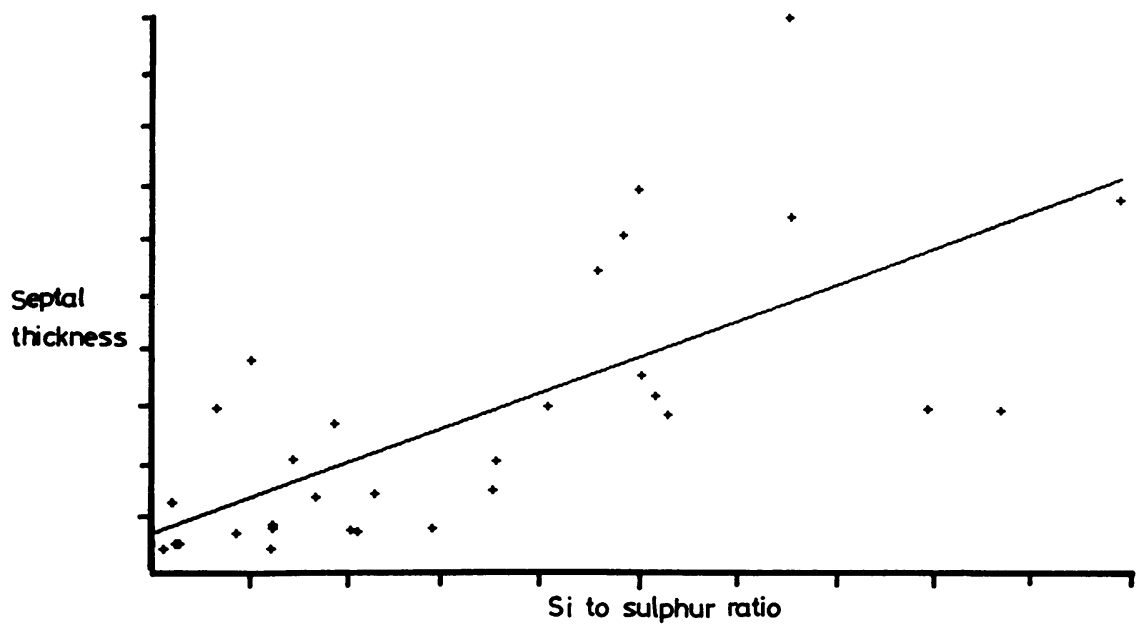

Si $Y=459.305 X+68.7089 \quad$ Coff of det $=0.496711$

Enter the symbol of the element for the comparison (CR-end)

Fig 4 Correlation curve for silicon versus septal thickness. 


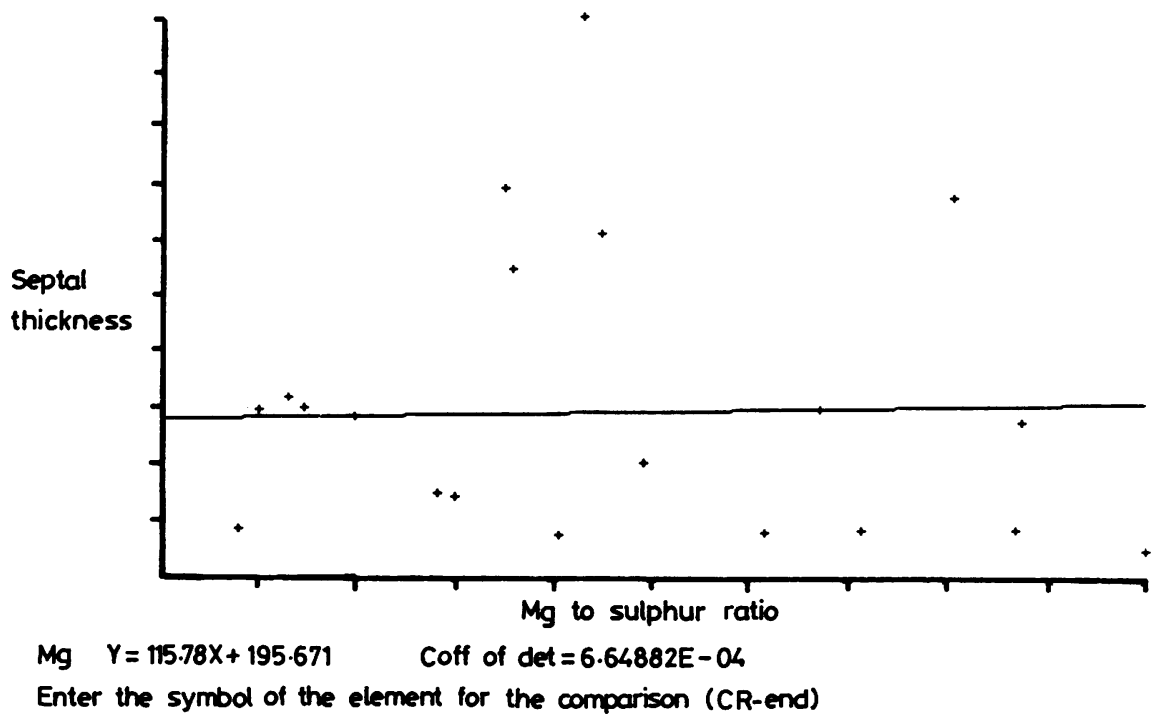

Fig 5 Correlation curve for magnesium versus septal thickness.

obtained from energy dispersive $x$ ray analysis of interalveolar septa this earlier study established a ratio of below 0.2 as a normal level, 0.2 to 0.3 as a raised level, and above 0.3 as a level of silicon that is consistent with silicosis.

\section{MORPHOMETRIC PROCEDURE}

A total of 13 cases of silicosis and five normal con- trols was evaluated. All of the control lungs examined were taken from necropsy specimens of individuals who had died of non-pulmonary causes. The silicotic lungs examined were taken from eight necropsy and five biopsy specimens. The site from which the necropsy tissue was taken was not known. All biopsy tissue was taken from the right middle lobe.

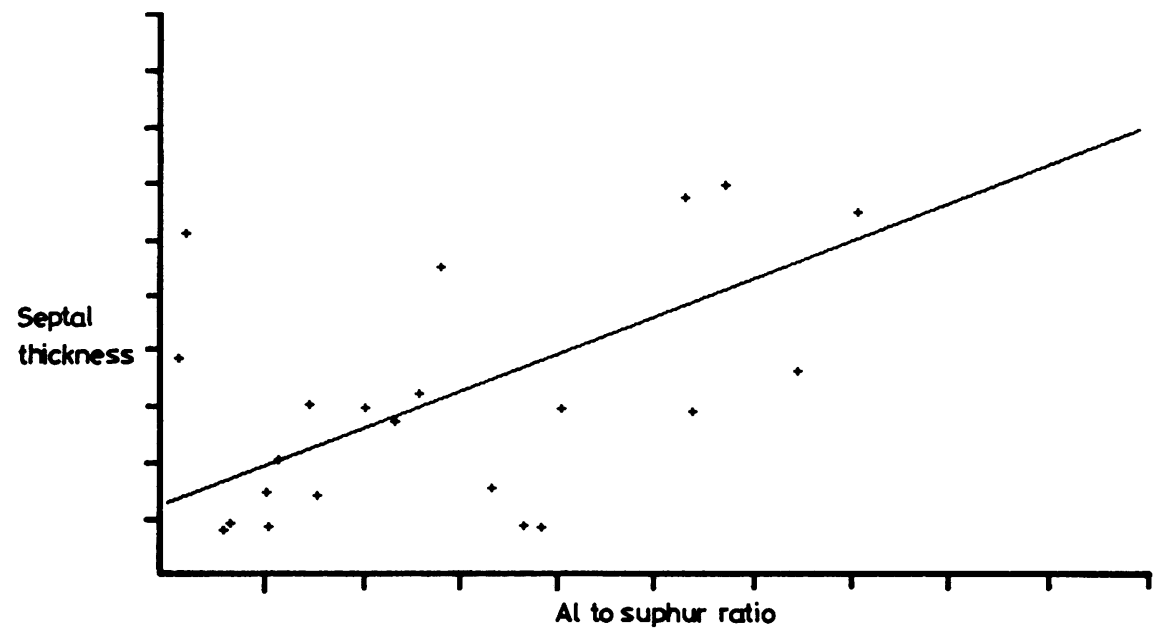
Al $Y=1186.19 X+83.7133$
Coff of det $=0.531014$

Enter the symbol of the element for the comparison (CR-end)

Fig 6 Correlation curve for aluminum versus septal thickness. 
Table 1 Correlation between elemental content and septal thickness

\begin{tabular}{lll}
\hline Element & Correlation coefficient & $p$ Value $(\leqslant)$ \\
\hline $\mathrm{Na}$ & 0.09 & $0 \cdot 1$ \\
$\mathrm{Mg}$ & 0.03 & $0 \cdot 1$ \\
$\mathrm{Al}$ & 0.73 & 0.0001 \\
$\mathrm{Si}$ & 0.70 & 0.0001 \\
$\mathrm{P}$ & 0.63 & 0.001 \\
$\mathrm{Cl}$ & 0.05 & 0.1 \\
$\mathrm{~K}$ & 0.35 & 0.05 \\
$\mathrm{Ca}$ & 0.15 & 0.1 \\
$\mathrm{Mn}$ & 0.29 & 0.05 \\
$\mathrm{Fe}$ & 0.31 & 0.05 \\
$\mathrm{Cu}$ & 0.06 & 0.1 \\
\hline
\end{tabular}

In order to determine septal thickness from the scanning electron micrographs a digitiser pad and a Talos smart box interfaced with a Cromemco System III, 64k computer were used. Five scanning electron micrographs were taken from each case examined. The average septal thickness in the areas analysed was calculated by averaging the width (linear) of 20 septal measurements chosen at random by the computer using a transparent grid overlay placed on the electron micrograph (fig 2). A computer program then randomly selected one of the $\mathrm{X}$ and one of the $\mathrm{Y}$ coordinates on the overlay. If the coordinate intercepted a septum the width of that septum was measured at that point using the digitising pad and the data were automatically stored in the computer. If the coordinate intercepted an alveolar space then another coordinate was selected until 20 measurements were attained. Figure 3 shows the cathode ray tube display of the grid system with the 20 individual septal measurements. The average septal thickness of these 20 measurements was then calculated and compared directly with the silicon concentration of the septa in this particular field. The computer program was used to determine if a correlation existed between the ele-

Table 2 Concentration of elements in normal lung at 100 $\times$ magnification (element/S ratio $\times 10^{-3}$ )

\begin{tabular}{lcc}
\hline & \multicolumn{2}{c}{ E/S units } \\
\cline { 2 - 3 } Element & Average & $+3 S D$ \\
\hline $\mathrm{Mg}$ & 5 & 13 \\
$\mathrm{Al}$ & 8 & 45 \\
$\mathrm{Si}$ & 64 & 148 \\
$\mathrm{P}$ & 672 & 1056 \\
$\mathrm{~S}$ & - & 91 \\
$\mathrm{Cl}$ & 34 & 82 \\
$\mathrm{~K}$ & 28 & 680 \\
$\mathrm{Ca}$ & 362 & 49 \\
$\mathrm{Mn}$ & 19 & 630 \\
$\mathrm{Fe}$ & 192 & 211 \\
$\mathrm{Cu}$ & 58 & 153 \\
$\mathrm{Zn}$ & 48 & \\
\hline
\end{tabular}

mental content of the septa and the septal thickening in the same field. The coefficients of correlations were calculated for each element found in the lung. Data were stored on two dual 8 "floppy discs under the appropriate label and viewed on a Tektronix 4025 terminal with graphics capability. A Tektronix 4652 hard copier and Diablo 1640 printer were used for hard copy.

\section{Results}

\section{MORPHOMETRY MEASUREMENTS}

Septal measurements were made using the talos digitiser pad as described and the data stored in the computer. Eighteen cases ( 5 controls and 13 silicotics) were examined. At least one area from each control or silicotic case was examined. In four cases of silicosis the extent of fibrosis was so severe that no useful data could be obtained. An attempt was made to photograph areas varying in degree from moderate to high regions of fibrosis. It is recognised that the absolute septal thickness of the septum cannot be measured in 30 micrometer thick sections. The average relative septal thickness of control lungs, however, using a grid system, was $16 \mu \mathrm{m}$.

The coefficients of correlation were calculated for each element found in the silicotic lungs. A correlation of $0.71(\mathrm{p}<0.0001)$ was found between $\mathrm{Si}$ and septal thickening (fig 4). This correlation is based on measurements from 22 different areas of varying? degrees of fibrosis. The positive slope of the curve suggests that a good correlation exists between the silicon content and the thickness of the septa.

By comparison, the coefficient of correlation for magnesium was $\mathbf{0} \cdot 02$. The graph of this correlation (fig 5) was extremely flat by comparison with silicon. The only other element with a high correlation was aluminium (fig 6) where a coefficient of correlation of 0.73 was determined. Table 1 shows the correlations of 11 different elements with septal thickness. The $p$ values for each element indicate the significance of the relationship of each element to septal thickness.

Since both $\mathrm{A} 1$ and $\mathrm{Si}$ showed a high correlation with septal thickness, a correlation was determined for silicon after the removal of all the high aluminium cases. Only those cases with less than three standard deviations above the mean of aluminium were included in the new calculations. After removal of the six high A1 cases the correlation coefficient for $\mathrm{Si}$ and septal thickness remained significant at $0.58(\mathrm{p}<0.05)$. The correlation coefficient of A1 to septal thickness, however, was only $0 \cdot 16$ (not significant). This suggests that high aluminium levels are not necessary for the correlation between silicon and septal thickening. 


\section{CALCULATION OF NORMAL VALUES OF} ELEMENTS IN LUNG

A selection was made of five random areas of lung from 20 normal individuals without evidence of pulmonary disease. These areas were analysed and the average values for all measurable elements calculated.

The concentration of the elements were expressed as ratios of the number of $\boldsymbol{x}$ ray counts of element divided by the $x$ ray counts for sulphur. This compensates for both section thickness and counting time. The derived ratio was then multiplied by $10^{-3}$ and expressed as $\mathrm{E} / \mathrm{S}$ units (element/sulphur). Using this technique, for example, the average silicon concentration in lung would be a silicon/sulphur ratio of 0.064 or $64 \mathrm{E} / \mathrm{S}$ units.

Table 2 shows the normal values for each element detected in the lung sections. The standard deviation of each element was calculated and a value of +3 standard deviations above the norm was arbitrarily selected as being raised for any particular element. As already stated, a Si value of $300 \mathrm{E} / \mathrm{S}$ units was previously determined to be diagnostic for silicosis. Elements not listed in the table cannot be detected by energy dispersive $x$ ray analysis in lungs at a $100 \times$ magnification. Although some elements foreign to the lung may be detectable below 5 $\mathrm{E} / \mathrm{S}$ units, only elements $10 \mathrm{E} / \mathrm{S}$ units or above are normally reported as raised.

\section{Discussion}

The use of element/sulphur ratios to express the amount of substances in the lung was particularly important since low power analyses of the lung show considerable variation in tissue mass for each area analysed. The use of sulphur as an internal standard to account for tissue mass provides a more reliable indication of the actual elements present in a unit mass of septa. ${ }^{25} 26$

It is recognised that the normal levels of elements reported in the lung sections represent only those elements which are not extracted through the preparation procedures. It is also possible that organic substances, not detectable by this method, could be reported in the lung sections represent only those the method is the inability to identify the form of the element in the human lung sections. The implication that a substance is producing fibrosis must, therefore, be made with caution when using human material where there is no history of exposure to a particular substance.

Although the cases studied here are well documented cases of exposure to silica, it is usually not possible, without using individual particle analysis, to distinguish between silicate and silica. The high $(p<0.001)$ correlation of phosphorus with septal thickening was not unexpected since fibrotic areas contain high concentrations of macrophage cells. Nuclei from dead macrophage cells probably contribute phosphorus to the high readings. This has been seen by us in the analysis of areas of high cellularity such as tumours that also show high phosphorus content. Since phosphorus is not a foreign element in tissue it is most likely not a cause of fibrosis.

The high correlation of silicon to septal thickening or fibrosis was not surprising since many studies have clearly shown that many forms of crystalline silica can produce fibrosis.

Many of the silicotics included in this study were foundry workers who were also exposed to high levels of iron. In view of this it is interesting to note that although iron levels were high in some of the lungs, iron showed a poor correlation to the thickened septal areas. This is consistent with earlier studies which showed iron and silicon deposited in different locations in lung septa. ${ }^{25}$

The high correlation of aluminium to septal thickening was interesting in view of several reports of aluminium pneumoconiosis..$^{27-30}$ It should be noted, however, that all the high aluminium areas also contained moderate to high levels of silicon. Removal of the high aluminium areas still provided a good correlation of silicon to septal thickness but aluminium no longer correlated to septal thickening $(0 \cdot 16)$. This suggests that low levels, at least of aluminium, do not produce significant septal thickening. Goralewski's view that high levels of aluminium may cause fibrosis of the lung ${ }^{31}$ could not be tested since none of our high Al cases was without high levels of silicon.

The technique described in this paper could be of value in evaluating the fibrogenicity of pure substances on animal lungs. The determination of element/fibrosis correlations provides a relatively simple and rapid means of evaluating the fibrogenic potential of substances. A correlative study may be possible with short exposure times and with only a moderate thickening of the septa. This would be of particular value when working with animal models where septa are usually thin. The early detection of septal thickening by this method would make the use of inhalation chambers more practical and would provide for a more physiological environment than intratracheal injection. Since small increases in septal thickness can be determined easily, the requirement for prolonged inhalation studies could be avoided. The use of inhalation chambers would also prevent the uneven distribution of substances among the various lobes. 


\section{References}

' Heppleston AG, Styles JA. Activity of a macrophage factor in collagen formation by silica. Nature 1967;214:521-2.

${ }^{2}$ Heppleston AG. The fibrogenic action of silica. Br Med Bull 1969;25:282-7.

${ }^{3}$ Kilroe-Smith TA, Webster I, Van Primmelen M, Marasas L. An insoluble fibrogenic factor in macrophages from guinea pigs exposed to silica. Environ Res 1973;6:298-305.

4 Aalto M, Potila M, Kulonen E. The effects of silica-treated macrophages on the synthesis of collagen and other proteins in vitro. Exp Cell Res 1976;97:193-202.

s Aalto M, Kulonen E. Fractionation of connective-tissueactivating factors from the culture medium of silica-treated macrophages. Acta Pathol Microbiol Immunol Scand (C) 1979;87:241-50.

- Burrell R, Anderson M. The induction of fibrogenesis by silicatreated alveolar macrophages. Environ Res 1973;6:389-94.

${ }^{7}$ Hefner RE Jr, Gehring PJ. A comparison of the relative states of hemolysis induced by various fibrogenic and nonfibrogenic particles with washed rat erythrocytes in vitro. Am Ind Hyg Assoc J 1975; 36: 734-40.

${ }^{8}$ Ligacz J, Paradowski Z. Hemolytic activity of aluminum and its compounds. Med $\operatorname{Pr} 1$ 1973;23:41-5.

9 Morgan A, Holmes A, Talbot RJ. The hemolytic activity of some fibrous amphiboles and its relation to their specific surface areas. Ann Occup Hyg 1977;20:39-48.

${ }^{10}$ David A. Hemolysis in vitro in the study of fibrogenity of industrial dusts. Int Arch Occup Environ Health 1976;37:289-300.

" David A, Hurych J, Effenbergerova E, Holusa R, Simecek J. Laboratory testing of biological activity of ore mine dust: fibrogenicity, cytotoxicity and hemolytic activity. Environ Res 1982;24:140-51.

12 Adamis Z, Timar M. Studies on the effect of quartz, bentonite and coal dust mixtures on macrophages in vitro. $B r J$ Exp Pathol 1978;59:411-5.

${ }^{13}$ Harington JS, Allison AC, Badami DV. Mineral fibers: chemical, physiochemical and biological properties. Adv Pharmacol Chemother 1975; 12:291-402.

${ }^{14}$ Schlipkotu HW, Beck EG. Observations on the relationship between quartz cytotoxicity and fibrogenicity while testing the biological activity of synthetic polymers. Med Law 1965;56: 485-93.

is Kysela B, Robock K, Weiss Z, Skoda V. Relations of some physical characteristics of quartz to fibrogenicity and cytotoxicity. In: 3rd symposium on experimental silicosis 1974. Ostrava:
Dum Techniky CVTS, 1974:5-17. (In Czechoslovakian.)

16 Dauber JH, Bossman MD, Pietra GG, Jimenez SA, Daniele RP. Morphologic and biochemical abnormalities produced by intratracheal instillation of quartz into guinea pig lungs. $\mathrm{Am}$ Pathol 1980; 101:595-607.

17 Davies JM. The fibrogenic effects of mineral dusts injected into the pleural cavity of mice. Br J Exp Pathol 1972;53:190-201.

${ }^{18}$ Gro P, Villiers AJ, de Treville TP. Experimental silicosis. Arch Pathol 1967;84:87-94.

${ }^{19}$ Heppleston AG, Wright NA, Stewart JA. Experimental alveolar lipoproteinosis following the inhalation of silica. J Pathol 1970; 101:293-307.

${ }^{20}$ Burns CA, Zarkower A, Ferguson FG. Murine immunological and histological changes in response to chronic silica exposure. Environ Res 1980;21:298-307.

21 Juva K, Prockop DJ. Modified procedure for the assay of $\mathrm{H}^{3}$ - or $C^{14}$ - labeled hydroxyproline. Anal Biochem 1966;15:77.

${ }^{22}$ Richards RJ, Tetley TD, Hunt J. The biological reactivity of calcium silicate composites: in vivo studies. Environ Res 1981;26: 243-57.

${ }^{23}$ Lewis DM, Burrell $R$. Induction of fibrogenesis by lung antibody-treated macrophages. $\mathrm{Br} J$ Ind Med 1976;33:25-8.

${ }^{24}$ Dauber JH, Rossman MD, Pieha GG, Jimenez SA, Daniele RP. Experimental silicosis, morphologic and biochemical abnormalities produced by intratracheal instillation of quartz into guinea pig lungs. Am J Pathol 1980; 101:595-612.

${ }^{25}$ Funahashi A, Siegesmund KA, Dragen RF, Pintar K. Energy dispersive $x$-ray analysis in the study of pneumoconiosis. $B r J$ Ind Med 1977;34:95-101.

${ }^{26}$ Siegesmund KA. Elemental content in alveolar septa in various pneumoconioses. (SEM/1980/II, SEM Inc.) Chicago; AMF O' Hare, 1980: 485-91.

27 Jordan JW. Pulmonary fibrosis in a worker using an aluminum powder. Br J Ind Med 1961;18:21-3.

${ }^{28}$ Mitchell J, Manning GB, Molyneux M, Lane RE. Pulmonary fibrosis in workers exposed to finely powdered aluminum. $\mathrm{Br} J$ Ind Med 1961;18:10-20.

${ }^{29}$ Vallyathan V, Bergerson WN, Robichaux PA, Craighead JE. Pulmonary fibrosis in an aluminum arc welder. Chest 1982;81:372-4.

${ }^{30}$ McLaughlin AIG, Kazantzis G, King E, Leare D, Porter RJ, Owen R. Pulmonary fibrosis and encephalopathy associated with the inhalation of aluminum dust. $\mathrm{Br} J$ Ind Med 1962; 19:253-63.

${ }^{31}$ Goralewski G. The aluminum lung: a new industrial disease. $Z$ Gesamte Inn Med 1947;2:665-73. 